13

\title{
Спектроскопические исследования эволюции фрактальных нанообъектов в пленкообразующих золях ортокремниевой кислоты
}

\author{
(c) И.А. Аверин, ${ }^{1}$ С.Е. Игошина, ${ }^{1}$ А.А. Карманов, ${ }^{1}$ И.А. Пронин, ${ }^{1,2,}$ В.А. Мошников, ${ }^{1,2}$ Е.И. Теруков ${ }^{3}$ \\ ${ }^{1}$ Пензенский государственный университет, \\ 440026 Пенза, Россия \\ ${ }^{2}$ Санкт-Петербургский государственный электротехнический университет «ЛЭТИ», \\ 197376 Санкт-Петербург, Россия \\ ${ }^{3}$ Физико-технический институт им. А.Ф. Иоффе РАН, \\ 194021 Санкт-Петербург, Россия \\ ฯ e-mail: pronin_i90@mail.ru
}

(Поступило в Редакцию 18 января 2018 г.)

В рамках метода ИК спектроскопии исследована эволюция среднего размера и концентрации наночастиц фрактальной природы, образующихся и динамически изменяющихся в ходе реакций гидролитической поликонденсации. Показано, что использование модели быстрой коагуляции Смолуховского совместно с анализом интенсивности характеристических линий поглощения в ИК спектрах позволяет получить удовлетворительную оценку эволюционных процессов, протекающих в золях ортокремниевой кислоты. Проведено качественное сопоставление полученных спектроскопических закономерностей и экспериментальных данных атомно-силовой микроскопии.

DOI: $10.21883 /$ JTF.2018.11.46639.32-18

\section{Введение}

В настоящее время золь-гель технология получения наноматериалов $[1,2]$, при всей своей простоте и доступности, скрывает в себе обширные возможности по управлению на молекулярном уровне процессами, протекающими в пленкообразующем золе. Данная технология позволяет синтезировать нанообъекты и иерархически организованные наноструктуры, обладающие комплексом уникальных свойств например, сверхразвитой поверхностью. Классическими процессами, лежащими в основе золь-гель синтеза, является кислый или щелочной гидролиз алкоксидов металлов и кремния с последующей поликонденсацией [3]. При этом продукты гидролиза сильно отличаются по структуре и свойствам в зависимости от условий проведения реакций гидролитической поликонденсации. Достоверно установлено, что для полимерных золь-гель систем характерна фрактальная природа структурной организации, при которой из единичных фрагментов продуктов гидролиза образуются компактные или разветвленные нано- и микрообъекты, вплоть до гигантского кластера $[4,5]$. Например, в работе [6] показано, что при использовании алкоксильных прекурсоров (тетраэтоксисилана или тетраметоксисилана) и щелочного катализатора (гидроксида аммония) удается добиться устойчивого синтеза коллоидной суспензии наноразмерных частиц диоксида кремния.

Для исследования процессов, протекающих в пленкообразующем золе, используются разнообразные аналитические методы, включая малоугловое рассеяние рентгеновских лучей (МУРР), динамического рассеяния света (ДРС) и другие. Однако данные методы при всех достоинствах позволяют провести анализ только некоторых аспектов процессов, протекающих в золях сложного состава, и не могут быть использованы для оценки полной картины, так как она является не статичной и претерпевает эволюционные изменения. Так метод МУРР может применяться для определения фрактальной размерности нанообъектов путем анализа общей кривой рассеяния в области Порода [7]. Кроме того, он позволяет по интенсивности рассеяния в области предельно малых углов установить значение концентрации мономеров в пленкообразующем золе и среднечисловой степени полимеризации. При этом МУРР не обеспечивает получение структурной информации непосредственно перед переходом „золь-гель“, т.е. вблизи точки гелеобразования.

Известный в настоящее метод ДРС широко используется при исследовании моно- и полидисперсных материалов, в том числе коллоидных золей [8]. ДРС основано на анализе временной автокорреляционной функции флуктуации интенсивности рассеянного излучения и позволяет исследовать структуру и динамику жидких сред, в том числе определять функции распределения по размерам коллоидных частиц. Согласно основам данного метода, прохождение лазерного излучения через анализируемую жидкость, содержащую взвешенные дисперсные частицы, приводит к рассеянию света на флуктуациях концентрации числа частиц, которые участвуют в броуновском движении. При этом в соответствии с гипотезой Онзагера используют первый закон Фика для описания релаксации микроскопических флуктуаций концентраций к равновесному состоянию. Данный подход, являясь допустимым для моно- или полидисперсных частиц, не применим для оценки эволюции фракталь- 
ных нанообъектов в пленкообразующих золях сложного состава, поскольку не учитывает их реальную форму и иерархическое строение.

На современном этапе развития диагностических методов исследования наноструктур инфракрасная спектроскопия является не только классическим методом определения их качественного и количественного состава $[9,10]$, но и содержит обширный потенциал, связанный c анализом структурных изменений наноматериалов. Цель настоящей работы заключается в разработке методов оценки эволюции среднего размера и концентрации наночастиц фрактальной природы, образующихся и динамически изменяющихся в ходе реакций гидролитической поликонденсации. Выбор золей ортокремниевой $\left(\mathrm{Si}(\mathrm{OH})_{4}\right)$ кислоты в качестве предмета исследований обусловлен не только их типичным составом и структурой, отвечающих полимерным золям на основе алкоксисоединений кремния, но и востребованностью в производстве наноструктурированных функциональных слоев. Например, на их основе изготавливаются пассивирующие слои и диэлектрические матрицы из диоксида кремния. Также модифицированные продуктами гидролиза алкоксидов металлов золи ортокремниевой кислоты используются при создании чувствительных элементов газовых сенсоров $[11,12]$ и датчиков вакуума [13].

\section{Методика эксперимента}

В качестве прекурсоров для синтеза золей $\mathrm{Si}(\mathrm{OH})_{4}$ использовался этиловый эфир ортокремниевой кислоты тетраэтоксисилан $\left(\mathrm{Si}\left(\mathrm{OC}_{2} \mathrm{H}_{5}\right)_{4}\right.$, TЭОС), простой спирт $(\mathrm{ROH}$, где $\mathrm{R}$ - углеводородный радикал) - этанол, пропанол, изопропанол и дистиллированная вода, выступающая в роли источника ОН-групп для гидролиза. Для смещения $\mathrm{pH}$ в кислую среду в качестве катализатора применялась соляная кислота $(\mathrm{HCl})$. Синтез проводился в два этапа: на первом смешивали ТЭОС и простой спирт при объемном соотношении $\mathrm{Si}\left(\mathrm{OC}_{2} \mathrm{H}_{5}\right)_{4}: \mathrm{ROH}$ $\left(V_{S}\right)-3: 1 ; 2: 1 ; 1: 1 ; 1: 2 ; 1: 3 ; 1: 9$, а на втором добавляли дистиллированную воду при молярном соотношении $\mathrm{Si}\left(\mathrm{OC}_{2} \mathrm{H}_{5}\right)_{4}: \mathrm{H}_{2} \mathrm{O}-1: 1.05$ и $\mathrm{HCl}$ объемом $50 \mu \mathrm{L}$.

В кислой среде при добавлении воды в спиртовой раствор ТЭОС достаточно быстро протекает реакция гидролитической поликонденсации. Гидролиз тетраэтоксисилана представляет собой реакцию биомолекулярного нуклеофильного замещения. Молекула воды взаимодействует с молекулой ТЭОС, приобретая частично положительный заряд, вследствие чего положительный заряд алкоксигруппы уменьшается, приводя к отщеплению молекулы спирта [14]:

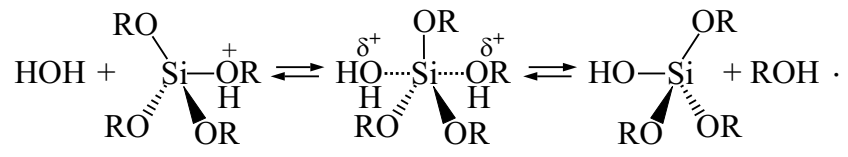

Процесс поликонденсации полученных продуктов гидролиза упрощенно описывается известной схемой [15]:<smiles>C[Si](C)(O)O[Si](C)(C)CC[Si](C)(C)O[PH3+]</smiles>

В результате протекания данных реакций в золях ортокремниевой кислоты образуются линейные слабо разветвленные полимеры, которые в результате переплетения и перекрестного связывания образуют нанообъекты с фрактальным типом структурной организации, а именно массовые (объемные) фракталы.

Достоверное исследование образования и эволюции нанообъектов в полимерных золях достаточно затруднено, поскольку гидролитическая поликонденсация является сложным параллельно-последовательным процессом, многие стадии которого, особенно ранние, обратимы за счет протекания реэтерификации и алкоголиза. Решение данной задачи возможно за счет объединения математического моделирования и спектроскопического анализа, протекающих процессов самоорганизации [16].

Исследование синтезированных золей проводилось на ИК фурье-спектрометре ФСМ 1201 (ООО „Инфраспек“, Россия) с использованием приставки многократного нарушения полного внутреннего отражения МНПВО36 с призмой $\mathrm{ZnSe}$. Измерения осуществлялись в спектральном диапазоне $650-4350 \mathrm{~cm}^{-1}$ с разрешением $4 \mathrm{~cm}^{-1}$. Для предотвращения испарения золей кювета закрывалась газонепроницаемым покрытием и экранировалась от прямого солнечного излучения.

Для верификации разработанных методов оценки эволюции среднего размера и концентрации наночастиц в золях ортокремниевой кислоты проводилось качественное сопоставление полученных спектроскопических закономерностей и данных атомно-силовой микроскопии в рамках порогового метода. Образцы для исследования готовились путем нанесения пленкообразующих золей на подложки из окисленного монокристаллического кремния размером $10 \times 10 \mathrm{~mm}^{2}$ методом центрифугирования (при скорости $4000 \mathrm{rpm})$, с последующим отжигом в воздушной атмосфере (в течение $30 \mathrm{~min}$, при $550^{\circ} \mathrm{C}$ ). Предполагалось, что в процессе термической обработки средний размер нанообъектов изменяется не более чем на $25 \%$, что согласуется с ранее полученными данными [17].

\section{Математическая модель эволюции фрактальных нанообъектов}

В рамках работы предполагалось, что в процессе эволюции (созревания и старения) золей из единичных фрагментов продуктов гидролиза образуются нанообъекты с фрактальной структурой, самосборка которых описывается моделью диффузионно- лимитированной агрегации (DLA). Конечным продуктом являются агрегаты Виттена-Сандера с фрактальной размерностью $D=2.5$. 

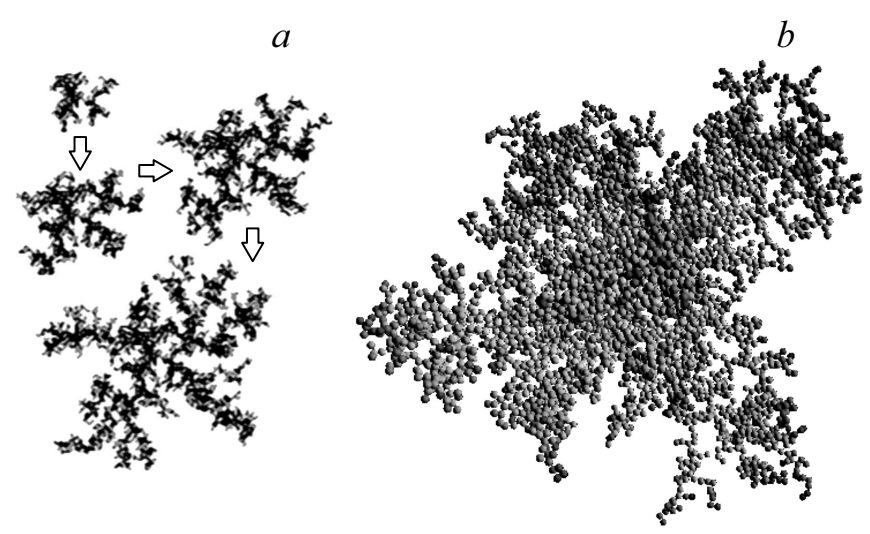

Рис. 1. Двумерная (a) и трехмерная (b) модель фрактала Виттена-Сандера.

Рис. 1 демонстрирует последовательные этапы сборки двумерного фрактала Виттена-Сандера, включающего 5000 частиц и его трехмерную модель соответственно [18].

Следует отметить, что кластер-кластерная агрегация, протекающая на поздних этапах созревания золей, не учитывалась в настоящей работе. Данное допущение обусловлено как конечным временем анализа эволюционных процессов, так и экспериментальными данными, подтверждающими влияние простых спиртов на термодинамическую стабильность золей. Тогда средний размер фрактальных нанообъектов в рамках модели DLA, определяется как [19]

$$
\bar{d}=\alpha^{\prime} d_{0} \bar{N}^{1 / D},
$$

где $\alpha^{\prime}$ - коэффициент, отражающий переход массового фрактала в поверхностный (в первом приближении $\left.\alpha^{\prime}=1\right) ; d_{0}-$ размер единичного фрагмента гидролиза (мономера); $\bar{N}-$ среднее число частиц в агрегате в момент времени $t$.

Для определения $\bar{N}$ целесообразным представляется использование модели быстрой коагуляции Смолуховского, согласно которой скорость убыли гидролизовавшихся частиц за счет процессов поликонденсации определяется уравнением:

$$
-\frac{d c}{d t}=K c^{2},
$$

где $K=\frac{4 k_{b} T}{3 \eta} \xi-$ константа быстрой коагуляции, $k_{b}-$ константа Больцмана, $T$ - абсолютная температура, $\eta-$ вязкость золя, $\xi$ - эффективная вероятность соударения.

Решение дифференциального уравнения (2) является гиперболическая функция времени:

$$
c(t)=\frac{c_{0}}{1+K c_{0} t}
$$

где $c_{0}$ - начальная концентрация наночастиц.
Тогда без учета процесса гидролиза среднее число частиц в агрегате в момент времени $t$ определяется как

$$
\bar{N}=\frac{c_{0}}{c(t)}=1+K c_{0} t .
$$

В зависимости от состава исследуемого пленкообразующего золя, условий его синтеза (pH среды, температуры и т.д.) уравнения, описывающие процесс гидролиза, могут значительно отличаться. Для рассматриваемых золей ортокремниевой кислоты экспериментально установлено, что при использовании в качестве катализатора соляной кислоты гидролиз ТЭОС в водно-спиртовой среде является реакцией второго порядка и описывается следующим уравнением [20]:

$$
-\frac{d N^{\prime}}{d t}=k\left(N_{\mathrm{H}_{2} \mathrm{O}}^{0}-N^{\prime}\right)\left(2 N_{\mathrm{TEOS}}^{0}-N^{\prime}\right),
$$

где $N^{\prime}$ - число молей гидролизовавшегося тетраэтоксисилана, $N_{\mathrm{H}_{2} \mathrm{O}}^{0}-$ начальная концентрация воды, $[\mathrm{mol} / \mathrm{l}]$, $N_{\mathrm{TEOS}}^{0}$ - начальная концентрация тетраэтоксисилана, [моль/л], $k$ - константа реакции, определяемая концентрацией соляной кислоты $[\mathrm{HCl}]$ :

$$
\lg (k)=\lg [\mathrm{HCl}]+\lg k^{\prime} .
$$

Коэффициент $k^{\prime}$ имеет смысл отношения константы реакции к концентрации хлористого водорода и для раствора тетраэтоксисилана в этаноле при $20^{\circ} \mathrm{C}$ приближенно равен 0.05 .

Совместное решение уравнений (3) и (5) позволяет описать поликонденсацию с учетом гидролиза, а как следствие этого, и эволюцию концентрации фрактальных нанообъектов в золях ортокремниевой кислоты. Для этого воспользуемся следующими допущениями:

- разобьем время протекания гидролитической поликонденсации на $n$ временных интервалов длительностью $\delta t$, внутри каждого из которых будет протекать только процесс поликонденсации, описываемый в соответствии с (3),

- в начале каждого временного интервала $\delta t_{i}$ (где $i=0,1,2, \ldots, t / n)$ в золь вбрасывается некоторое количество мономеров $\Delta_{i}$, сформированных путем гидролиза в соответствии с (5) на $i-1$ интервале.

Интегрирование уравнения (5) с учетом начальных условий вида $N^{\prime}(t=0)=0$ позволяет получить временную зависимость числа молей гидролизовавшегося ТЭОС:

$$
N^{\prime}=\frac{1-2 N_{\mathrm{TEOS}} N_{\mathrm{H}_{2} \mathrm{O}} \exp \left(k\left(N_{\mathrm{H}_{2} \mathrm{O}}-2 N_{\mathrm{TEOS}}\right) t\right)}{2 N_{\mathrm{TEOS}}-N_{\mathrm{H}_{2} \mathrm{O}} \exp \left(k\left(N_{\mathrm{H}_{2} \mathrm{O}}-2 N_{\mathrm{TEOS}}\right) t\right)} .
$$

Выражение (7) с учетом рассмотренных допущений преобразуется к следующему виду для каждого временного интервала $\delta t_{i}$ :

$$
N_{i}^{\prime}=\frac{1-2 N_{\mathrm{TEOS}} N_{\mathrm{H}_{2} \mathrm{O}} \exp \left(k\left(N_{\mathrm{H}_{2} \mathrm{O}}-2 N_{\mathrm{TEOS}}\right) i \delta t\right)}{2 N_{\mathrm{TEOS}}-N_{\mathrm{H}_{2} \mathrm{O}} \exp \left(k\left(N_{\mathrm{H}_{2} \mathrm{O}}-2 N_{\mathrm{TEOS}}\right) i \delta t\right)} .
$$




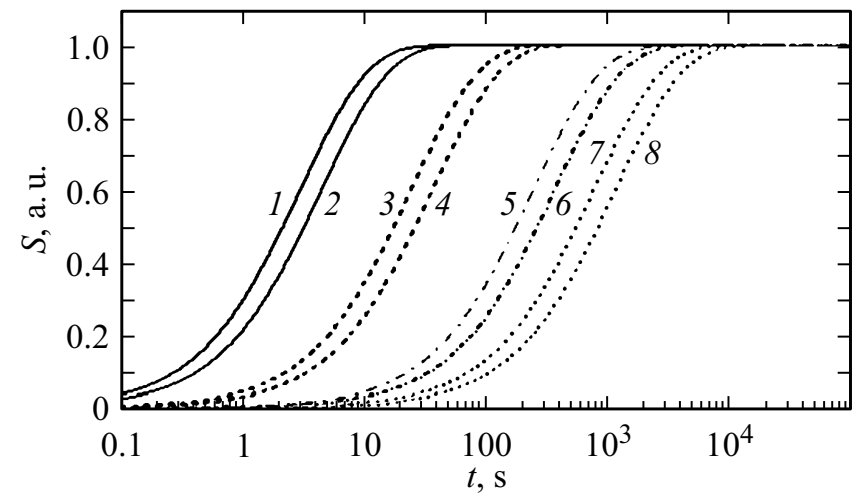

Рис. 2. Степень гидролиза ТЭОС как функция времени при различном $\mathrm{pH}$ среды: $1,2-0.09,3,4-1,5,6-2,7,8-$ 2.5 и соотношении ТЭОС: $1,3,5,7-V_{S}=1: 1,2,4,6,8-$ $V_{S}=1: 2$.

Тогда количество мономеров, вбрасываемых в момент времени $i \delta t$, определяется выражением

$$
\Delta_{i}=N_{i}^{\prime}-N_{i-1}^{\prime} .
$$

Для оценки влияния кислотности среды на ход процесса гидролиза показательно изменение количества воды, израсходованной на процесс гидролиза, т.е. разность $(a-b)$ между числом молей воды, вступившей в реакцию по схеме:

$$
-\stackrel{\mathrm{S}}{\mathrm{S}}-\mathrm{OC}_{2} \mathrm{H}_{5}+a \mathrm{H}_{2} \mathrm{O} \longrightarrow-\underset{\mathrm{S}}{\mathrm{I}}-\mathrm{OH}+\mathrm{C}_{2} \mathrm{H}_{5} \mathrm{OH},
$$

и числом молей воды, выделившейся при конденсации по схеме:

$$
-\underset{\mid}{\mathrm{Si}}-\mathrm{OH}+\mathrm{HO}-\mathrm{Si}-\rightarrow-\underset{\mid}{\mathrm{Si}}-\mathrm{O}-\underset{\mid}{\mathrm{Si}}-+b \mathrm{H}_{2} \mathrm{O} .
$$

На рис. 2 представлена временная зависимость степени гидролиза тетраэтоксисилана $(S-$ относительное число молей гидролизовавшегося ТЭОС) при различном значении $\mathrm{pH}$ среды и объемном соотношении $\mathrm{Si}\left(\mathrm{OC}_{2} \mathrm{H}_{5}\right)_{4}: \mathrm{C}_{2} \mathrm{H}_{5} \mathrm{OH}$.

Из рис. 2 видно, что степень, а следовательно, и скорость гидролиза ТЭОС сильно зависит от кислотности среды. При увеличении рН она сильно замедляется, причем при $\mathrm{pH}>3$ процесс не завершается в течение десятков часов (кривые 7 и 8). В сильнокислой среде $($ при $\mathrm{pH}<1)$ данная реакция протекает достаточно быстро и уже в течение первого часа (при избытке воды) все молекулы ТЭОС являются гидролизованными и образуют молекулы ортокремниевой кислоты, вступающие в реакцию поликонденсации (кривые $1-4)$. В слабокислой среде скорость гидролиза уменьшается, а следовательно, значительно увеличивается возможность полной конденсации гидроксильных групп по мере их образований. В результате чего образуются кремнийорганические полимеры, практически не содержащие гидроксильных групп. Данное обстоятельство позволяет использовать уравнение Смолуховского для описания эволюции среднего размера и концентрации наночастиц фрактальной природы. Объемное соотношение $\mathrm{Si}\left(\mathrm{OC}_{2} \mathrm{H}_{5}\right)_{4}: \mathrm{C}_{2} \mathrm{H}_{5} \mathrm{OH}$ оказывает на скорость гидролиза меньшее влияние, чем pH среды. Однако явно прослеживается замедление данной реакции при увеличении содержания простого спирта, который выполняет стабилизирующую функцию, задавая термодинамическую устойчивость золей.

Исходя из данных замечаний, концентрация фрактальных нанообъектов в золе во временном интервале $\delta t_{i+1}$ с учетом (9) определяется как:

$$
c_{i+1}=\frac{c_{i}+\Delta_{i}}{1+K\left(c_{i}+\Delta_{i}\right) \delta t} .
$$

Среднее число частиц в агрегате во временном интервале $\delta t_{i+1}$ по аналогии с (4):

$$
\bar{N}_{i+1}=c_{0} \frac{1+K\left(c_{i}+\Delta_{i}\right) \delta t}{c_{i}+\Delta_{i}} .
$$

Средний размер фрактальных нанообъектов в рамках модели DLA во временном интервале $\delta t_{i+1}$ с учетом (11):

$$
\bar{d}_{i+1}=\alpha^{\prime} d_{0} \bar{N}_{i+1}^{1 / D} .
$$

На рис. 3 представлена временная зависимость $c$ и $\bar{d}$, рассчитанная в рамках предложенной математической модели, для пленкообразующих золей ортокремниевой кислоты при различном значении $\mathrm{pH}$ среды и объемном соотношении $\mathrm{Si}\left(\mathrm{OC}_{2} \mathrm{H}_{5}\right)_{4}: \mathrm{C}_{2} \mathrm{H}_{5} \mathrm{OH}-1: 1$. Анализ полученных зависимостей показывает, что концентрация фрактальных нанообъектов является нелинейной функцией времени, для которой можно выделить три основных участка. При малых значениях времени наблюдается близкий к монотонному рост, обусловленный преобладающим влиянием гидролиза над поликонденсацией. С течением времени скорость гидролиза уменьшается и становится сопоставимой со скоростью второго из рассмотренных процессов, что выражается в наличии на зависимостях участка с постоянным значением концентрации фрактальных нанообъектов. Дальнейшие динамические изменения в золе связаны прежде всего с поликонденсацией, в ходе которой единичные нанообъекты слипаются, образуя фрактальные агрегаты, описываемые моделью Виттена-Сандера.

Такое поведение временной зависимости концентрации фрактальных нанообъектов полностью соответствует изменению их среднего размера, который на ранних этапах синтеза растет достаточно медленно, а на более поздних существенно ускоряется (рис. $3, b$ ). С увеличением времени созревания золей рост $\bar{d}$ постепенно начинает замедляться, что обусловлено уменьшением эффективной вероятности соударения частиц друг с другом, вследствие падения их концентрации [21]. Кислотность среды не оказывает значительного влияния 

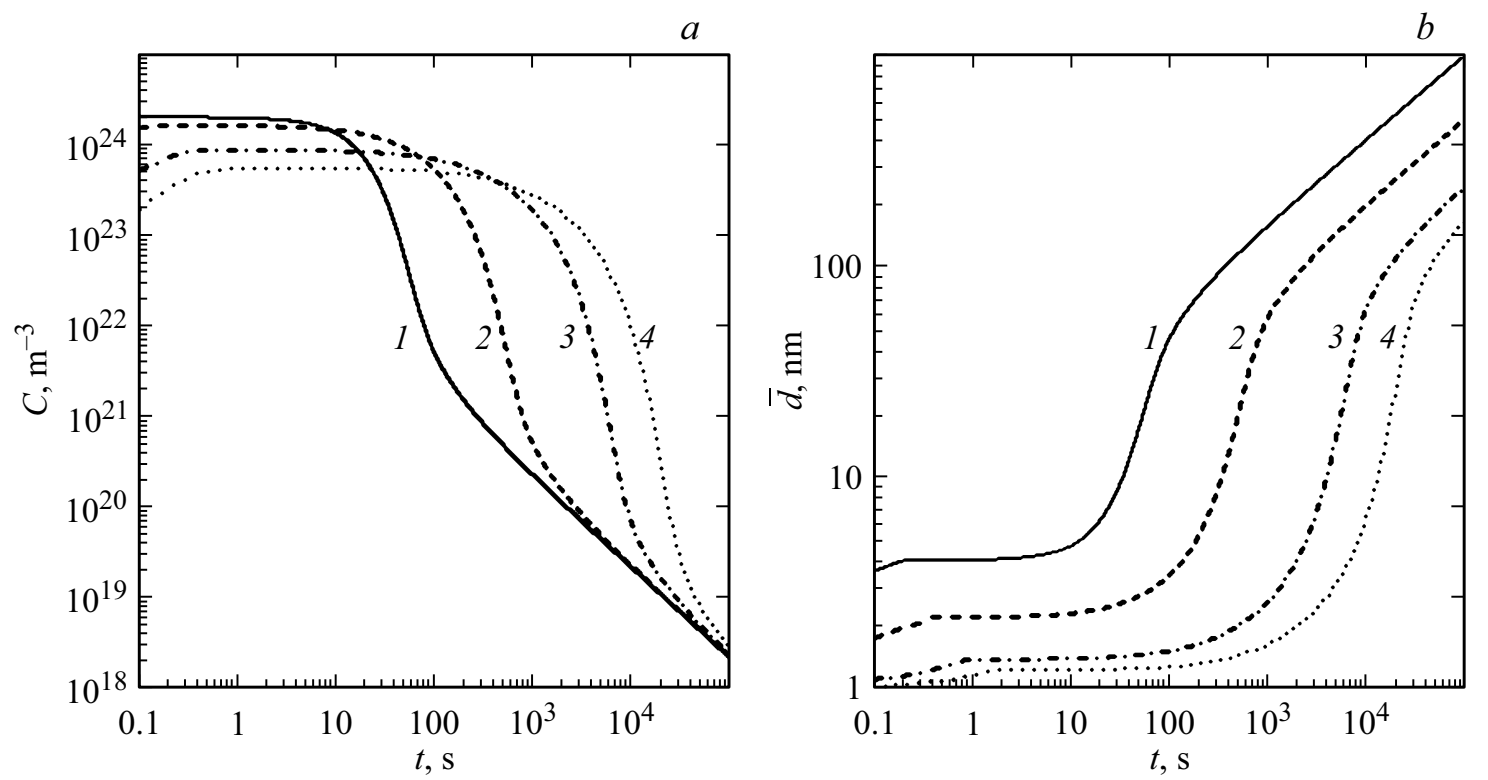

Рис. 3. Временная зависимость концентрации $(a)$ и среднего размера $(b)$ фрактальных нанообъектов в пленкообразующих золях ортокремниевой кислоты при различной кислотности среды: $1-0.09,2-1,3-2,4-2.5$.

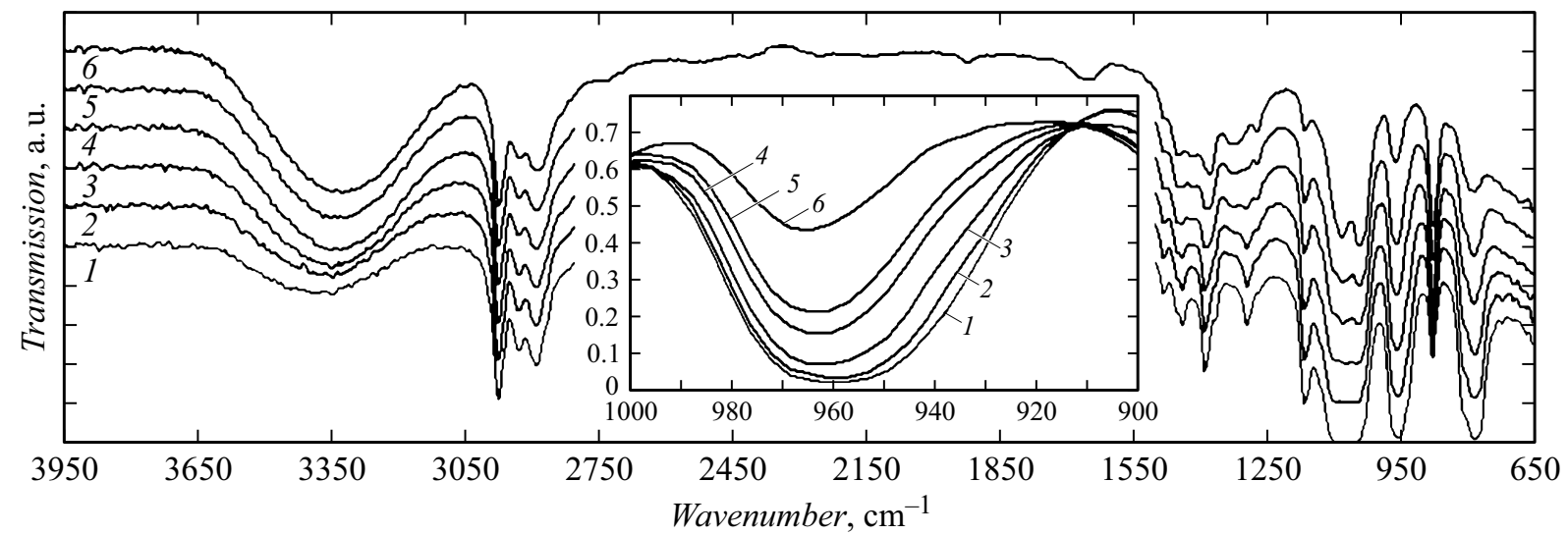

Рис. 4. ИК спектры пропускания пленкообразующих золей ортокремниевой кислоты с различной начальной концентрацией наночастиц: $1-2.0 \cdot 10^{27}, 2-1.8 \cdot 10^{27}, 3-1.3 \cdot 10^{27}, 4-9.0 \cdot 10^{26}, 5-6.7 \cdot 10^{26}, 6-2.7 \cdot 10^{26} \mathrm{~m}^{-3}$.

на вид кривых, однако определяет продолжительность каждого из рассмотренных участков и время перехода от одного к другому.

\section{Спектроскопические исследования эволюции фрактальных нанообъектов}

На первом этапе спектроскопических исследований проанализированы ИК спектры пропускания пленкообразующих золей ортокремниевой кислоты с различной начальной концентрацией наночастиц (рис. 4). Синтезированы и изучены образцы с объемным соотношением $\mathrm{Si}\left(\mathrm{OC}_{2} \mathrm{H}_{5}\right)_{4}: \mathrm{C}_{2} \mathrm{H}_{5} \mathrm{OH}\left(V_{S}\right)-3: 1 ; 2: 1 ; 1: 1$; $1: 2 ; 1: 3 ; 1: 9$, которое отвечает значениям начальной концентрации $c_{0}$, лежащим в диапазоне от $2.7 \cdot 10^{26} \mathrm{~m}^{-3}$ до $2.0 \cdot 10^{27} \mathrm{~m}^{-3}$ (при исходном объеме ТЭОС $-1 \mathrm{ml}$ ).
ИК спектры исследуемых золей содержат ряд характеристических полос и пиков поглощения, отвечающих

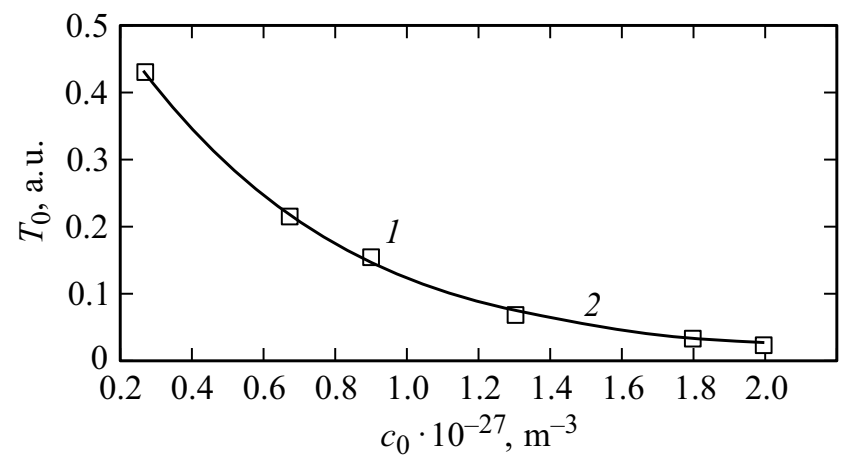

Рис. 5. Взаимосвязь коэффициента пропускания и начальной концентрации наночастиц (на пике поглощения $\left.960 \mathrm{~cm}^{-1}\right): 1-$ экспериментальные, 2 - аппроксимация. 


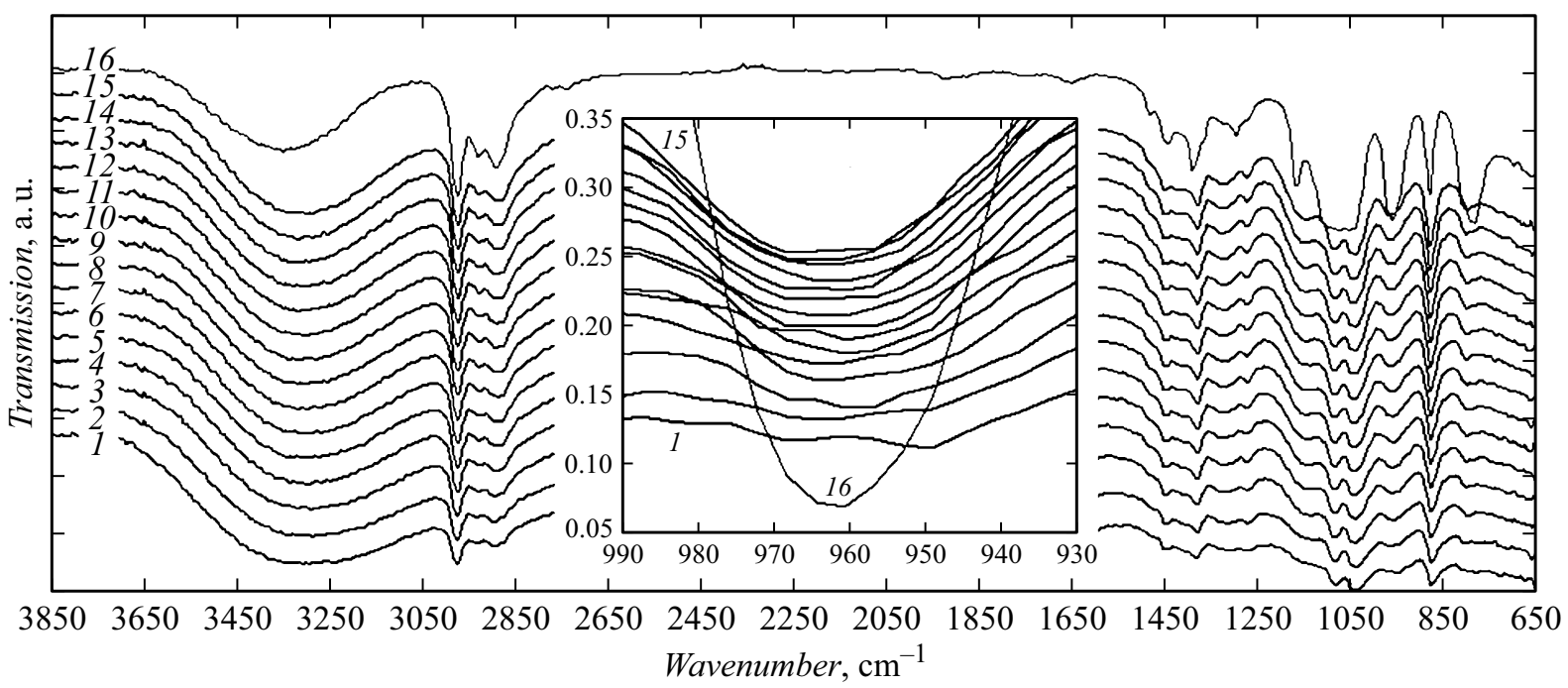

Рис. 6. ИК спектры пропускания пленкообразующих золей ортокремниевой кислоты при различном времени после начала процесса гидролитической поликонденсации: $1-30,2-60,3-120,4-240,5-360,6-480,7-600,8-720$, $9-960,10-1200,11-1500,12-1800,13-2400,14-3000,15-3600 \mathrm{~s} ; 16-$ нулевой момент времени.

их качественному составу, детальная идентификация которых изложена в работе [22]. С точки зрения исследования эволюции фрактальных нанообъектов основной интерес представляют моды при 960 и $1080 \mathrm{~cm}^{-1}$, соответствующие валентным симметричным колебаниям связей $\mathrm{Si}-\mathrm{OH}$ и $\mathrm{Si}-\mathrm{O}-\mathrm{Si}$ соответственно. Первая из рассмотренных мод отвечает процессу гидролиза ТЭОС,

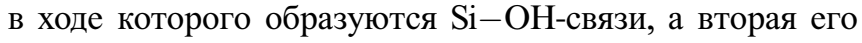
поликонденсации, в результате которой формируется кислородный мостик между атомами кремния. Вставка на рис. 4 демонстрирует спектральные зависимости коэффициента пропускания для гидролизующегося ТЭОС с различным значением $c_{0}$. На их основе может быть получена взаимосвязь коэффициента пропускания (в минимуме) и начальной концентрации наночастиц (рис. 5).

Анализ полученной зависимости показывает, что с ростом $c_{0}$ доля ИК излучения, проходящего через исследуемые пленкообразующие золи, значительно уменьшается. Данное обстоятельство полностью согласуется с известным законом Бугера-Ламберта-Бера и позволяет аппроксимировать представленные экспериментальные данные экспоненциальной функцией следующего вида:

$$
T_{0}\left(c_{0}\right)=a_{0} \exp \left(-a_{i} c_{0}\right)+a_{2}
$$

где $\quad a_{0}=0.687, \quad a_{1}=1.716 \cdot 10^{-27} \mathrm{~m}^{3}, \quad a^{2}=7.217$ $\times 10^{-4}-$ константы аппроксимации.

Данная зависимость позволяет определить начальную концентрацию наночастиц при замедленном процессе гидролитической поликонденсации, что достигается в условиях нейтрального рН среды, т.е. до добавления в раствор соляной кислоты, выступающей в качестве катализатора и уменьшающей значения $\mathrm{pH}$.

На втором этапе спектроскопических исследований проанализированы ИК спектры пропускания пленкооб-

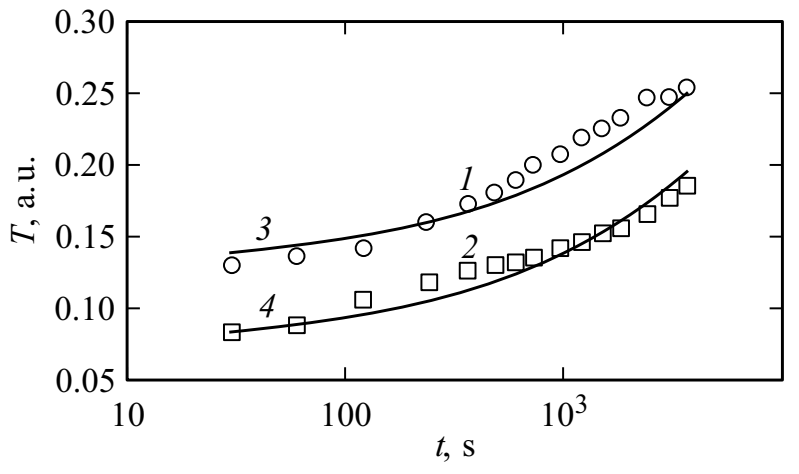

Pис. 7. Временная зависимость коэффициента пропускания для золей ортокремениевой кислоты после начала процесса гидролитической поликонденсации: 1 - экспериментальные данные при $c_{0}=9 \cdot 10^{26} \mathrm{~m}^{-3}, 2-$ экспериментальные данные при $c_{0}=1.3 \cdot 10^{27} \mathrm{~m}^{-3}, 3,4-$ аппроксимация.

разующих золей ортокремниевой кислоты, подверженные динамическим изменениям, т.е. при протекании гидролитической поликонденсации (рис. 6). Синтезированы и изучены образцы с объемным соотношением $\mathrm{Si}\left(\mathrm{OC}_{2} \mathrm{H}_{5}\right)_{4}: \mathrm{C}_{2} \mathrm{H}_{5} \mathrm{OH}\left(V_{S}\right)-1: 1$ и $1: 2$, т. е. имеющие начальную концентрацию наночастиц $1.3 \cdot 10^{27} \mathrm{~m}^{-3}$ и $9 \cdot 10^{26} \mathrm{~m}^{-3}$ соответственно.

Из рис. 6 видно, что в процессе гидролитической поликонденсации происходит значительное изменение интенсивности характеристических линий поглощения, отвечающих валентным симметричным колебаниям связей $\mathrm{Si}-\mathrm{OH}$ и $\mathrm{Si}-\mathrm{O}-\mathrm{Si}$ соответственно. В спектральном диапазоне 930-990 $\mathrm{cm}^{-1}$ (с минимумом $960 \mathrm{~cm}^{-1}$ ) наблюдается увеличение доли проходящего ИК излучения, а в диапазоне $1020-1120 \mathrm{~cm}^{-1}$ (с минимумом $1080 \mathrm{~cm}^{-1}$ ) ее уменьшение, что является след- 

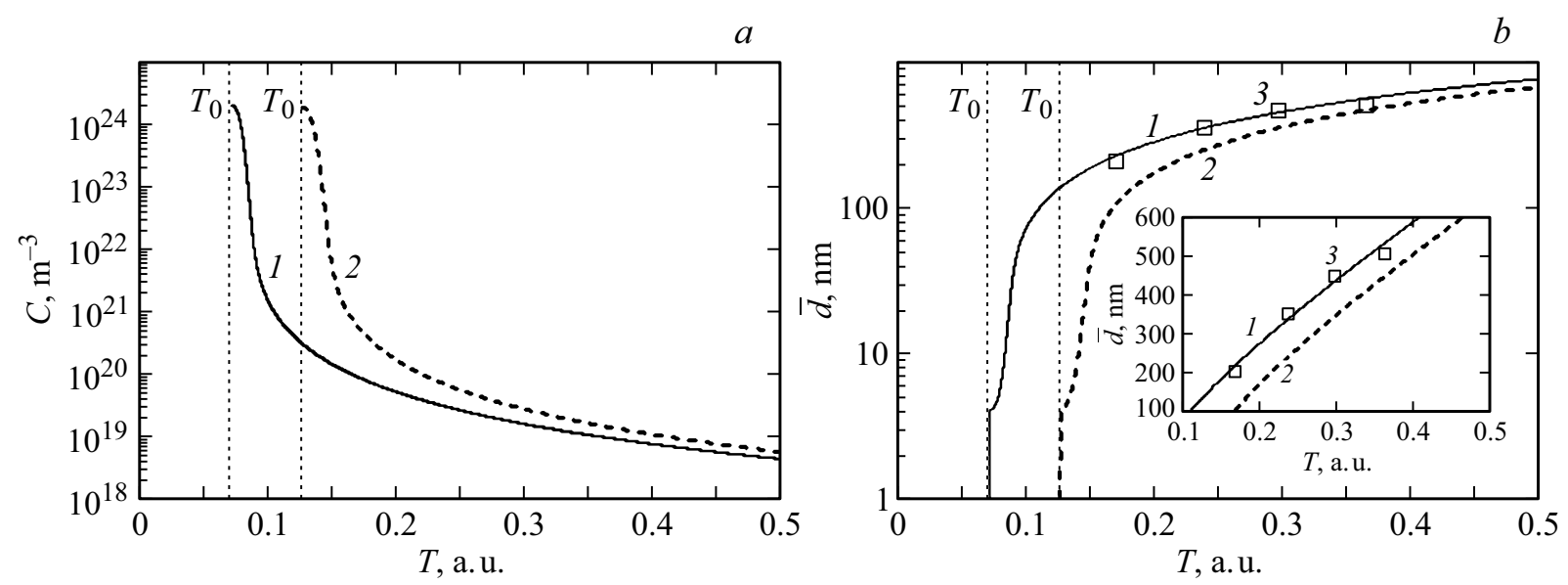

Рис. 8. Зависимости концентрации $(a)$ и среднего размера $(b)$ фрактальных нанообъектов в золе ортокремневой кислоты от коэффициента пропускания ИК излучения при различной начальной концентрации наночастиц: $1-1.3 \cdot 10^{27}, 2-9 \cdot 10^{26} \mathrm{~m}^{-3}$, 3 - экспериментальные данные АСМ.

ствием самосборки фрактальных нанообъектов. Вставка на рис. 6 демонстрирует спектральные зависимости коэффициента пропускания для золей ортокремниевой кислоты $\left(c_{0}=9 \cdot 10^{26} \mathrm{~m}^{-3}\right)$, претерпевающих последовательные стадии эволюции. На их основе может быть получена временная зависимость коэффициента пропускания (в минимуме), отражающая эволюционные процессы (рис. 7). ИК спектры пропускания образцов с отличной начальной концентраций наночастиц (например, при $c_{0}=1.3 \cdot 10^{27} \mathrm{~m}^{-3}$ ) в целом аналогичны представленным на рис. 6 спектрам.

Анализ приведенных временных зависимостей показывает, что для описания взаимосвязи коэффициента пропускания ИК излучения и времени с начала самосборки фрактальных нанообъектов может быть использована степенная функция следующего вида:

$$
T(t)=b \sqrt{t}+T_{0}
$$

где $b=2.236 \cdot 10^{-3},[1 / \sqrt{\mathrm{s}}]-$ некоторая константа, $T_{0}-$ коэффициент пропускания ИК излучения через золь ортокремневой кислоты до начала процесса гидролитической поликонденсации при различной начальной концентрации наночастиц (при $c_{0}=9.0 \cdot 10^{26} \mathrm{~m}^{-3}-$ $T_{0}=0.127$, при $\left.c_{0}=1.3 \cdot 10^{27} \mathrm{~m}^{-3}-T_{0}=0.072\right)$.

\section{Результаты и обсуждение}

Тот факт, что $c_{0}$ практически не влияет на вид рассмотренных зависимостей, а только лишь определяет $T_{0}$, указывает на однотипность протекающих процессов и полностью согласуется с результатами моделирования, согласно которым временные зависимости концентрации (рис. 3) сходятся к некоторой совпадающей величине. Исходя из этого, может быть получена функциональная зависимость, связывающая коэффициент пропускания ИК излучения через пленкообразующий золь, а также концентрацию и средний размер фрактальных нанообъектов. Для ее построения используется сопоставление $c_{i}$ и $\bar{d}_{i}$ значению $T_{i}$ в начале каждого временного интервала $\delta t_{i}$ (рис. 8).

Анализ полученных зависимостей показывает, что росту коэффициента пропускания ИК излучения через золь ортокремниевой кислоты соответствует уменьшение концентрации фрактальных нанообъектов, средний размер которых растет за счет процесса самосборки. Начальная концентрация наночастиц отвечает значению $T_{0}$, при котором наблюдается наименьший размер агрегатов, и наибольшая их концентрация, которая, однако, не соответствует $c_{0}$, а определяется процессом гидролиза.

Для верификации предложенных модельных представлений использовалось качественное сопоставление полученных спектроскопических закономерностей и экспериментальных данных атомно-силовой микроскопии с использованием порогового метода [23]. Оценивалась величина $\bar{d}_{i}$ и ее изменение в ходе протекания эволюционных процессов. На рис. 9 представлены АСМизображения морфологии поверхности наноструктур, синтезированных из золей с различным временем созревания. Каждому из образцов отвечает собственное значение коэффициента пропускания ИК излучения: 0.171 , $0.239,0.297$ и 0.366 соответственно. Вставка на рис. $8, b$ демонстрирует наложение экспериментальных данных ACM на характерную кривую среднего размера.

Из анализа АСМ-изображений видно, что общая тенденция укрупнения фрактальных нанообъектов при увеличении времени после начала процесса гидролитической поликонденсации сохраняется, однако единичных агрегаты могут иметь размер, значительно превышающий средний. Данное обстоятельство обусловливается как неполным соответствием модели DLA образованию и росту наночастиц, так и не учтенными процессами, отвечающими нанесению золя на подложки, его сушке, а также частичному и/или полному схлопыванию 

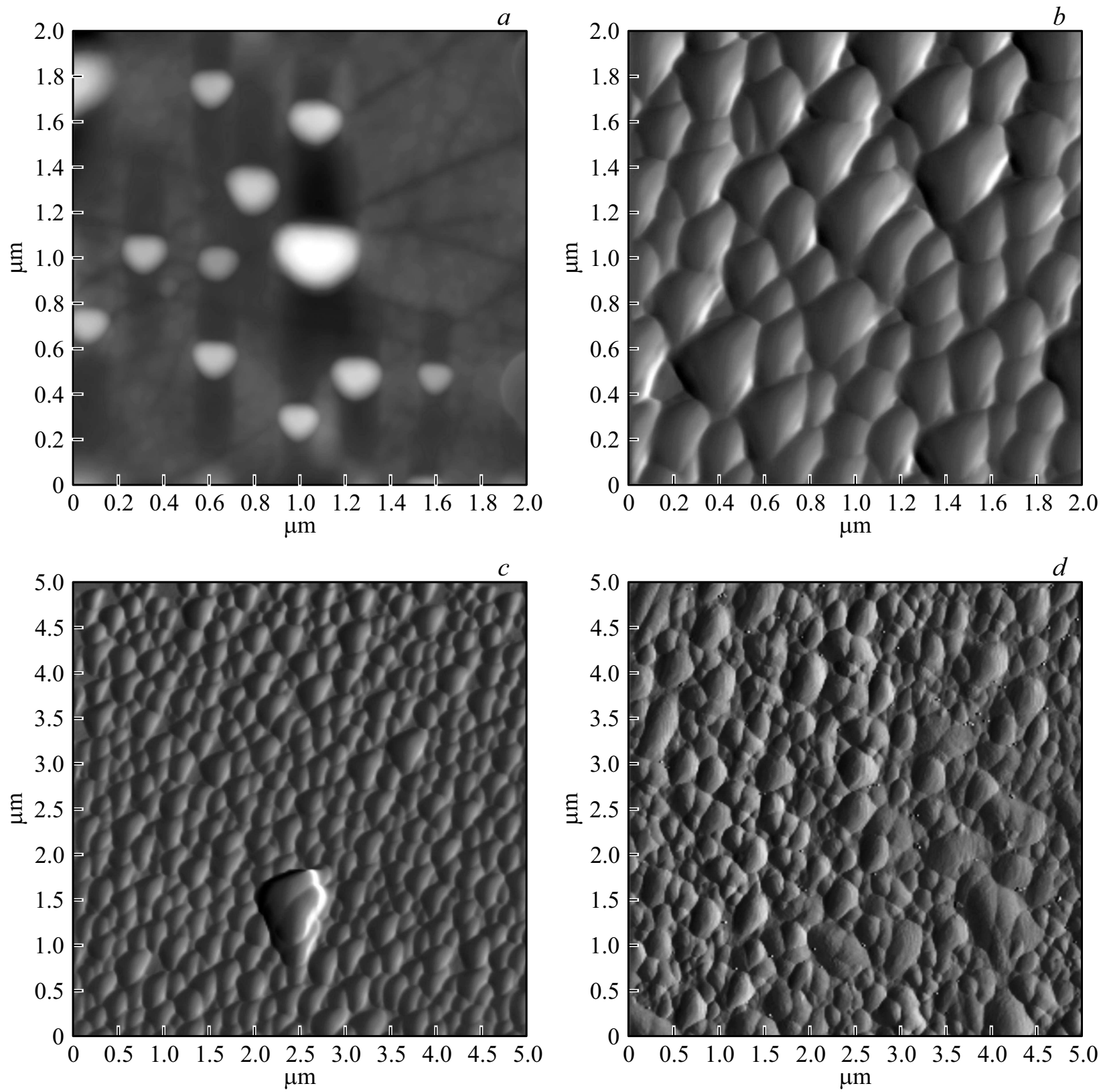

Рис. 9. АСМ изображения морфологии поверхности образцов, полученных из золей с различным временем созревания.

фрактальных агрегатов при отжиге. Однако в целом ошибка при определении $\bar{d}_{i}$ по спектроскопическим закономерностям не превышает $30 \%$, и может быть уменьшена за счета учета вышеизложенных допущений и использования более точных моделей самосборки, например кластер-кластерной агрегации.

\section{Выводы}

Таким образом, предложен метод оценки эволюции среднего размера и концентрации наночастиц фрактальной природы, образующихся и динамически изменяющихся в ходе реакций гидролитической поликонден- сации. В основе данного метода лежит объединение спектроскопических закономерностей, характеризующих коэффициент пропускания ИК излучения через исследуемый золь, и модельных представлений о самосборке фрактальных нанообъектов. Показано, что использование модели быстрой коагуляции Смолуховского совместно с анализом интенсивности характеристических линий поглощения в ИК спектрах позволяет получить удовлетворительную оценку эволюционных процессов, протекающих в золях ортокремниевой кислоты. Верификация результатов предложенного метода данными атомно-силовой микроскопии подтверждает адекватность использованных приближений. 
Работа выполнена при финансовой поддержке Министерства образования и науки РФ в рамках проектной части госзадания (проект № 16.897.2017/4.6), а также стипендии Президента РФ СП-3800.2018.1.

\section{Список литературы}

[1] Brinker C.J., Scherer G.W. Sol-Gel Science: The Physics and Chemistry of Sol-Gel Processing / Academic Press, 1990. $908 \mathrm{p}$.

[2] Мочников В.А., Грачева И.Е., Аньчков М.Г. // ФХС. 2011. T. 37. № 5. C. $672-684$. DOI: 10.1134/S1087659611050063 [Moshnikov V.A., Gracheva I.E., An'chkov M.G. // Glass Physics and Chemistry. 2011. Vol. 37. N 5. P. 485-495.]

[3] Петрова И.В., Шилова О.А. // ФХС. 2016. Т. 42. № 1. C. 75-85. DOI: 10.1134/S1087659616010119 [Petrova I.V., Shilova O.A. // Glass Physics and Chemistry. 2016. Vol. 42. N 1. P. 50-58.]

[4] Пронин И.А., Аверин И.А., Димитров Д.Ц., Карманов А.А. // Нано- и микросистемная техника. 2014. № 8. C. 3-7.

[5] Шилова О.А., Губанова Н.Н., Иванова А.Г., Арсентьев М.Ю., Уклеев В.А. // Журн. неорган. химии. 2017. T. 62. № 5. C. 650-657.

[6] Ciriminna R., Fidalgo A., Pandarus V., Beland F., Ilharco L.M., Pagliaro M. // Chem. Rev. 2013. Vol. 113. N 8. P. 6592-6620. DOI: $10.1021 / \mathrm{cr} 300399 \mathrm{c}$

[7] Kammler H.K., Beaucage G., Mueller R. // Langmuir. 2004. Vol. 20. N 5. P. $1915-1921$. DOI: $10.1021 / 1 \mathrm{a} 030155 \mathrm{v}$

[8] Куликов К.Г., Кошлан Т.В. // ЖТФ. 2015. Т. 85. Вып. 12. C. 26-32. DOI: 10.1134/S1063784215120099 [Kulikov K.G., Koshlan T.V. // Technical Physics. The Russian J. Appl. Phys. 2015. Vol. 60. N 12. P. 1758-1764.]

[9] Леньшин А.С., Кашкаров В.М., Середин П.В., Спивак Ю.М., Мошников В.А. // ФТП. 2011. Т. 45. Вып. 9. C. 1229-1234. DOI: 10.1134/S1063782611090168 [Lenshin A.S., Kashkarov V.M., Seredin P.V., Spivak Y.M., Moshnikov V.A. // Semiconductors. 2011. Vol. 45. N 9. P. 1183-1188.]

[10] Аверин И.А., Карманов А.А., Мошников В.А., Печерская Р.М., Пронин И.А. // Изв. вузов. Поволжский рег. Физ.-мат. науки. 2012. № 2. С. 155-162.

[11] Kadhim Imad H., Hassan Abu H., Abdullah Q.N. // NanoMicro Lett. 2016. Vol. 8. P. 20-28. DOI: https://doi.org/10.1007/s40820-015-0057-1

[12] Pronin I.A, Dimitrov D.TS, Krasteva L., Papazova K., Averin I.A, Chanachev A., Bojinova A., Georgieva A.TS., Yakushova N.D., Moshnikov V.A. // Sensors and Actuators A: Phys. 2014. Vol. 206. P. 88-96. DOI: https://doi.org/10.1016/j.sna.2013.11.035

[13] Аверин И.А., Игошина С.Е., Мошников В.А., Карманов А.А., Пронин И.А., Теруков Е.И. // ЖТФ. 2015. T. 85. Вып.6. С. 143-147. DOI: 10.1134/S106378421506002X [Averin I.A., Igoshina S.E., Karmanov A.A., Pronin I.A., Moshnikov V.A., Terukov E.I. // Techn. Phys. Rus. J. Appl. Phys. 2015. Vol. 60. N 6. P. 928-932.]

[14] Pronin I.A., Averin I.A., Yakushova N.D., Karmanov A.A., Moshnikov V.A., Ham M.-H., Cho B.K., Korotcenkov G. // Arab. J. Sci. Engineer. 2017. Vol. 42. N 10. P. 299-4305. DOI: https://doi.org/10.1007/s13369-017-2804-8
[15] Ng L.V., McCormick A.V. // J. Phys. Chem. 1996. Vol. 100. P. 12517-12531. DOI: 10.1021/jp960089o

[16] Третьяков Ю.Д. // Успехи химии. 2003. Т. 72. № 8. C. 731-762. DOI: https://doi.org/10.1070/RC2003v072n08 ABEH000836 [Tretyakov Y.D. // Rus. Chem. Rev. 2003. Vol. 72. N 8. P. 651-679.]

[17] Pronin I.A., Goryacheva M.V. // Surf. Coating. Technol. 2013. Vol. 235. P. 835-840. DOI: https://doi.org/10.1016/j.surfcoat.2013.09.009

[18] Мандельброт Б.Б. Множество Мандельброта и другие чудеса. М.-Ижевск: НИЦ „Регулярная и хаотическая динамика“, 2009. 392 с.

[19] Witten T.A., Sander L.M. // Phys. Rev. Lett. 1981. Vol. 47. P. $1400-1403$. DOI: https://doi.org/10.1103/PhysRevLett.47.1400

[20] Андрианов К.A. Кремнийорганические соединения. М.: Гос. н.-т. изд-во хим. лит-ры, 1955. 520 с.

[21] Peev N.S. // Bulg. J. Phys. 2014. Vol. 41. P. 291-304.

[22] Аверин И.А., Карманов А.А., Мошников В.А., Пронин И.А., Игошина С.Е., Сигаев А.П., Теруков Е.И. // ФТТ. 2015. T. 57. Вып. 12. С. 2304-2312. DOI: 10.1134/S10637 83415120069 [Averin I.A., Karmanov A.A., Pronin I.A., Igoshina S.E., Sigaev A.P., Moshnikov V.A., Terukov E.I. // Phys. Solid State. 2015. Vol. 57. N 12. P. 2373-2381.]

[23] Бухараев А.А., Зиганшина С.А., Чукланов А.П. // Рос. нанотехнологии. 2010. Т. 5. № 5-6. C. 87-94. DOI: https:// doi.org/10.1134/S1995078010050113 [Bukharaev A.A., Ziganshina S.A., Chuklanov A.P. // Nanotechnologies in Russia. 2010. Vol. 5. N 5-6. P. 364-376.] 